\title{
An Analysis of Recent Changes in Higher Education and Research in Albania
}

\author{
Prof. Asoc. Dr. Eriona Katro
}

\author{
Tirana University, European Studies Institute, Albania
}

Email: erionakatro@yahoo.it

\author{
Doi:10.5901/ajis.2015.v4n2s2p46
}

\begin{abstract}
Higher education is a public good as well as a public responsibility. It is realized from higher education institutions and is regulated by higher education legislation in the Republic of Albania. From January 2014 in Albania started a reform process in higher education and research. The way how this reform is realized is a particular way because the drafting of it is entrusted to an independent Commission. The Commission consists of academics and experts in higher education. The result of the reform consists in a draft law which abrogates the law no.9741, dated 21.5.2007 "On higher education in the Republic of Albania". The draft law has already initiated its legislative process. This paper seeks to be one of the first works that examines some of the innovations in this draft law. The draft consists of thirteen chapters. In my opinion two are the most important innovations. The first innovation relates to the proposal of a new way of organizing and functioning of institutions of higher education which clearly separates academic and administrative leadership. The highest academic governing body is the Academic Senate and the highest academic authority remains the Rector of the Institution which is its legal representative for academic affairs. The highest administrative governing body is the Board of Administration, which guarantees the fulfilment of the mission of the institution and its financial and administrative conduct. The draft law creates a new figure who is the administrator of the Institution who is the highest administrative authority responsible for the financial functioning of the institution. The administrator is the legal representative of the institution for financial and administrative matters. This paper will analyze the relationship between academic and administrative structures. A hotly debated innovation of the reform is the creation of another type of institution which is the Independent public institution of higher education known as a public legal person. The special thing about this institution is that it is created as a result of the transformation of the existing institutions of higher education, on their demand, but only when they meet preset criteria set by law. Can be transformed into public legal persons not only public institutions, but also non-public higher education. The new institution is non-profit and regardless of the origin of the foundation, the institution applies the same rules of organization. To the new institution will apply the provisions for public institutions of higher education in all cases when is not otherwise provided. The methodology used will be analytical.
\end{abstract}

Keywords: higher education, reform, research, higher education institutions, academic.

\section{Introduction}

Higher education and scientific research in Albania are involved in a wider reform process which started in January 2014 and is still going on ${ }^{1}$. The reform process has begun with the creation of the Commission for Reform in Higher Education and Research which consists of academics and experts in higher education. The main purpose of the Commission was the drafting of a concrete proposal for the reform and the preparation of a Detailed Report for the Implementation of the Reform. The purpose of the Commission is now accomplished. It is materialized in a draft law which abrogates the law no. 9741, dated 21.5.2007 "On higher education in the Republic of Albania". The draft law has already initiated its legislative process. The Report for the Implementation of the Reform is a medium-term objective. It will be prepared in a second moment, after the adoption of the new law on higher education and research. The way how this reform is realized is a particular way because of two aspects. The first aspect is connected with the composition of the Commission which consists of academics and independent experts in higher education. The second aspect relates to the participation in the reform process of academics, students, Higher Education Institutions and other interested subjects.

Further, to implement the Reform, the Commission has followed different methodologies known in the field of social policies, like the analysis of different sources of information, taken from the archives of the Ministry of Education and the archives of the Government, various libraries in the country and abroad, as well as other archival electronics

1 It refers to the time the author writes this paper. 
sources. It has carried out statistical analysis of secondary data of higher education in the country and has analysed the international contemporary literature on higher education and research. The Commission has initially estimated the situation of higher education in the country, areas of dysfunction of the law no. 9741, dated 21.5.2007 "On higher education in the Republic of Albania" and has concluded proposing a new regulation on higher education and research. The proposal will be analysed in this paper but the author wants to highlight that the analysis will focus only on the most important proposed changes. The draft law affects essential aspects of the organization and functioning of higher education system in Albania which changes the physiognomy and philosophy of the current higher education system.

\section{Research Methodology}

This is a theoretical research, based on the direct analysis of the draft law on higher education and research in Albania. Besides that, Albanian Constitution, Albanian law on higher education, Albanian Civil code and Decisions of the Albanian Constitutional Court concerning to the issue were analysed.

\section{An overview of the draft law on higher education and research in Albania}

The draft consists of thirteen chapters. The thirteenth chapter is dedicated to transitional provisions. At the time of entry into force, the new law will abrogate in toto law no.9741, dated 21.5.2007 "On higher education in the Republic of Albania". Does the draft law represent a novelty for the Albanian system? In fact the draft is based on a good portion of its provisions on provisions of law no. 9741 leaving them unchanged or just changed somehow. The choice of the Commission to draw up a comprehensive regulation that regulates the field of higher education and scientific research abolishing the previous regulation in the same field instead of a regulation that changes and adds the provisions of previous law, without abrogating it, has been a forced choice. The author claims that because of the many changes proposed by the draft law which required the drafting of a new regulation. The proposed draft division in chapters, it is not the same division of law no. 9741. Through the new structure of law the Commission aims to fill some gaps created by Law No. 9741. One of the lacks of the law no 9741, dated 21.5.2007, which can be mentioned, it is the fact that this law fully regulates higher public education while higher private education is regulated in a chapter consisting of few provisions. This situation has brought many problems related to the implementation of the law on private institutions of higher education. In the new draft this deficiency is completed. It clearly defines when provisions are implemented by all higher institutions, or only by public/ non-public or by independent public institutions.

\section{Analysis of the draft law on higher education and research}

The first chapter entitled "General Provisions" states that higher education is a public good as well as a public responsibility and defines its mission and purpose of the draft that aspires to transform into law. In this chapter, based on the provisions of the Constitution of the Republic of Albania, article 57, point 7 which states that "The autonomy of institutions of higher education and academic freedom are guaranteed by law", is recognized and guaranteed academic freedom and financial, organizational and personnel selection autonomy to all higher education institutions. This chapter explains also the ways through which this freedom and autonomy becomes effective. The right to higher education belongs to all those individuals who have successfully completed secondary education and meet the eligibility criteria set out in the legal framework and by institutions of higher education. This chapter states the obligation for the state to guarantee the right to higher education to all individuals who meet the eligibility criteria to attend a first cycle program, an integrated program or professional studies program, but do not have financial possibilities to deal with them. It will be the Council of Ministers that will determine the categories of individuals who will benefit from this right. The upper mentioned delegation transforms the state obligation into a flexible one because the guarantee level of the right to higher education will depend on educational policies of the Executive power. In this chapter it is defined the role of the state in higher education, its responsibilities and obligations. The state acts through its responsible organs and structures, in accordance with its regulatory functions and as the founder of higher public education and funding of higher education and research. The chapter concludes with the definitions of the most used terms used in the field of higher education and research. Some of the provisions of this chapter are not just introductory provisions, but also guarantee provisions like provision on autonomy or on right to higher education. In the author's view the provisions of this chapter are well-structured and in line with regulations on higher education in state members in the European Union.

In the second chapter entitled "The organization of higher education and scientific research" are defined the 
powers of the Ministry responsible for education², it is regulated the Council of Higher Education and Scientific Research and the Public Agency of accreditation in higher education which changes its name into Quality Assurance Agency for Higher Education. The agency empowers in terms of competence and independence that the draft law recognizes to it. The competences of the Ministry have changed only partially compared with law no. 9741. Some of them lead to discussion. For example, regarding the right to verify the legality of the conduct of elections in public higher education institutions the provision does not explain what happens if the Minister believes that elections are not held in the right way ${ }^{3}$. This chapter of the law creates three new public institutions that are Educational Service Centre, National Agency for Higher Education Financing and the National Agency of Research and Innovation, with specified competencies. It must be said that during the reform process the creation of these agencies has been debated by academics. One of the criticisms is related to their composition and way of functioning that are left to be defined and further regulated by the Council of Ministers or order of the Minister responsible for education. In relation with the importance of these institutions for academic and research activity of higher education institutions the law should define clearly their composition and way of functioning in order to guarantee the principle of legal certainty.

The third chapter entitled "Organization of higher education institutions" states that higher education institutions are organized into three categories: public, non-public and independent public institutions. Each category is further defined in draft law. These institutions are created, opened, organized, funded, accredited, evaluated, suspended and closed in accordance with the provisions of the draft law and regulations that will be adopted for its implementation after approval by the Parliament and promulgation by the President of the Republic. Types of higher education institutions are: universities, university colleges, academies and higher vocational colleges. For each type of them the draft clearly specifies features, programs that they can offer and their constituent units.

The fourth chapter regulates the opening, reorganization and closure of higher education institutions. The provisions of this chapter are more complete and clearer than the regulations of law n. 9741 on the same themes.

Fifth Chapter is a very important chapter. It proposes a new way of organizing and functioning of institutions of higher education which clearly separates academic and administrative leadership. The highest academic governing body is the Academic Senate and the highest academic authority remains the Rector of the Institution which is its legal representative for academic affairs. Other academic bodies are academic staff meeting and standing committees. Other academic Authorities are the leader of the main unit and the head of the base unit. The highest administrative governing body is the Board of Administration, which guarantees the fulfilment of the mission of the institution and its financial and administrative conduct. The draft law creates a new figure who is the administrator of the Institution who is the highest administrative authority responsible for the financial functioning of the institution. The administrator is the legal representative of the institution for financial and administrative matters. Other administrative Authorities are the administrator of the main unit and the administrator of the base unit.

In public institutions members of the academic senate and academic authorities are elected through a general election process, which takes place every four years. Board of Administration members and administrative Authorities are elected/ appointed according to the provisions of the draft law. Differently happens in higher non-public education institutions where members of the academic senate, academic authorities, board of administration members and administrative Authorities are elected/ appointed according to the provisions of the draft law and the regulation acts of the institution. For public institutions, the draft specifies prescriptive way of creating authorities and bodies of the institution while leaves non-public institutions free to decide how to form the same bodies and authorities. This is a situation that requires debate on it. We cannot forget that higher education is a public good as well as a public responsibility, regardless of the category of the institution which offers it. For this reason, the rules must be the same for both categories of institutions. The implementation of the electoral process in non -public HEI would avoid the possibility of investiture of structures by the owner of the institution. This investiture can place the bodies and authorities under the orders of the owner.

Regarding the relationship between academic and administrative structures the draft law aims to create a balanced way of functioning where the highest governing bodies, the senate and the board of administration coordinate their activities on an on-going basis and create the impression that the two bodies will work very closely in the future. The most important decisions in the institution seek the opinion of both bodies. We cannot leave without mentioning that the vision

\footnotetext{
2 Which is defined as the institution that carries out government program in the field of higher education and scientific research.

${ }^{3}$ Albanian constitutional court explains that Ministry's right to abrogate HE institutional Authorities and bodies acts, when these acts are contrary to law on higher education violates the principle of autonomy in HEI (Decision no. 9/2008). 
of this draft law is new since in the current vision of higher education the highest body is the academic one. The mission of higher education can be achieved primarily as a result of academic input. In this vision organs and administrative authorities are in the function of academic authorities and bodies.

A situation that deserves to be noted relates to the composition of the highest administrative body, which is the Board of administration. Board of administration in non- public HEI is composed of seven members. Some of them are representatives of $\mathrm{HEl}$, others are representative of the ministry responsible for education and local government. Composition of the Board is determined by the medium-term budget plan of public HEl. The draft law states that four members of the board will represent the HEl if it provides itself fifty per cent or more of the medium-term budget. The other three members will represent the ministry responsible for education and local government. In all cases where the institution itself provides less than fifty per cent of medium-term budget only three members will represent the HEI. In all the cases the local government will be represented in the board if it contributes financially, at least in the amount of ten per cent of medium-term budget plan of the $\mathrm{HEl}$.

These definitions should be analysed together with the competence of the Ministry to propose the minimum and maximum fee for first cycle program studies in public HEl. Participation of Ministry responsible for education in the Board of administration deserves a special analysis. The principal question is: is this participation a form of violation of financial autonomy of the institution? The Albanian constitutional court explains that academic self-government is reflected among others in choosing, independently ${ }^{4}$, the governing bodies..... the exercise of decision power constitutes an expression of the effectiveness of institutional autonomy...." (Decision no. 36/2007)

In our analysis we must consider some other facts like 1) the representation in the board depends on the level of funding; 2) institution incomes are mainly student fees; 3 ) the number of students in study programs is not free but it will be determined depending on different capacities of the institution and 4) Ministry proposes the minimum and maximum fee for first cycle program studies in public HEl. In these conditions, if the Ministry liked to have the majority on the Board, it will always reach it. It will be sufficient a very low proposal of maximum fees for first cycle program studies. This proposal will probably impede the institution to provide itself fifty per cent or more of the medium-term budget. However, these are hypotheses that will never happen in the presence of a Ministry that recognizes and respects the autonomy of higher education institutions. The draft, regarding non-public HEI uses a different standard and leaves them free to determine the composition of the board in their statutes. The above differentiation is based on the fact that state is the most important or the only funder of public $\mathrm{HEl}$. On the other hand it is true also that, non-public institutions may receive funds from the state, although these funds do not make the state a significant funder for these institutions. Higher education is a public good as well as a public responsibility and one way to accomplish this responsibility it could be the representation of the Ministry, with at least one representative member, in the board of non-public HEI. This participation, in terms of a Ministry, which recognizes and respects the autonomy of higher education institutions, will only bring positive consequences.

Chapter six regulates the staffs of higher education institutions which consist of academic staff, support academic staff and administrative staff. Regarding academic staff the draft specifies that it can be oriented on teaching and / or scientific research. Academic staff is categorized into: a) professors; b) lecturers and c) Assistant-Lecturers. In the category of "professors" are included members of academic staff, heads of subjects or modules and leader of scientific research activity. Academic staff members of this category hold academic titles "Professor" or "Associate Professor". In the category of "lectors" are included members of academic staff who conduct educational activities and scientific research. They hold the scientific degree "PhD", have at least three years of experience in teaching and meet the criteria set out in the statute of the HEl. Assistant-Lecturers are all members of academic staff that conduct teaching and research activities. They must have at least the degree "Master of science" and meet the criteria set out in the statute of the HEI. Full and minimal teaching workload for academic staff in public institutions is determined by the institution, in accordance with the relevant guidance of the minister responsible for education, while in non- public institutions minimal teaching workload is determined by the institution itself. The determination of the workload, in accordance with a guidance of the minister, can be understood as a violation of the institution autonomy. Which is the reason for above differentiation of teaching workload for academic staff, depending on the category of HEl? While the draft states that academic staff that enjoys special status and treatment, regardless of the institution where he/she is employed.

The draft provides a new system for obtaining academic degrees "Associate Professor" and "Professor". All the universities that meet criteria specified in the draft law have the power to give these titles. An important innovation in this

${ }^{4}$ Where among the governing bodies should be considered also the Board of Administration. 
chapter is also the provision that academic staff returns to its previous job, in case of unfair dismissal, when there is a court decision. The seventh chapter regulates the organization of studies in HEl providing two forms of studies: full-time and extended time studies (part-time). In contrast to the current system, extended time studies are not offered in the first cycle study programmes, Master of Science, $\mathrm{PhD}$ and specialisation programmes. Receipts of students in higher education institutions in all study programs are made by decision of the institutions, in accordance with state standards, the academic capacity and infrastructure. These standards are verified and certified by the ministry responsible for education. There are three study cycles: the first, second and third cycle. In the first cycle HEl offer bachelor programs, in the second cycle offer "Professional Master" and "Master of science" and in the second cycle offer "PhD", "long term specialisations" and "Executive Master". In comparison with the current system, the draft adds the "Executive Master", which reminds us the "Master of second level". Higher education institutions can offer also professional study programs.

Another innovation consists in requested criteria of grade point average (GPA) to be accepted in bachelor and integrated study programmes. The GPA is determined each year by the Council of Ministers. Another novelty of the draft is the fact that the application process to be accepted in bachelor, integrated study and professional programmes for all institutions of higher education is coordinated by the educational service centres. While admission to the second and third cycle programmes is conducted by HEl.

The eighth chapter regulates research in higher education institutions which can perform basic or applied research activities, studies and development projects and other creative activities. They ensure the integration of research into teaching activities. Scientific research activities can be conducted also by institutes and inter - institutional researchdevelopment centres. The ninth chapter regulates students, acquisition, suspension and loss of student status, student councils, students' rights and obligations, data and documentation of educational process. The tenth chapter regulates quality assurance in higher education. It stipulates that higher education institutions are responsible for developing policies and procedures for internal quality assurance, while external quality assurance in higher education is realized through external evaluation processes and accreditation, analytical and comparative evaluations, as well as other processes that promote and improve the quality instead. It is realised by Quality Assurance Agency for Higher Education. Another novelty is represented by the code of Higher Education Quality which is a main guide to all the processes and procedures of quality assurance in higher education. A very important chapter is no. eleven which regulates properties and higher education funding. It defines the sources of funding to public institutions of higher education. It introduces a new way of funding from the state budget. Incomes are distributed in three grant forms: development policies grant for public $\mathrm{HEI}$, teaching grant and scientific research and creative activities grant. Development policies grant for public $\mathrm{HEI}$ includes 1) institution and academic infrastructure supporting fund and 2) competing development projects HEl fund. Teaching grant includes 1) institucional fund for public HEI and 2) supporting students' fund. Scientific research and creative activities grant includes funds for research, covering also doctoral studies fund.

A hotly debated innovation of the reform is the creation of another kind of institution which is the Independent public institution of higher education known as a public legal person. This institution is regulated in chapter twelve. It is created as a result of the transformation of the existing institutions of higher education, on demand of non-profit foundations created for this purpose, but only when they meet pre-set criteria set by law. Can be transformed into public legal persons not only public institutions, but also non-public higher education. The new institution is non-profit and regardless of the origin of the foundation, the institution applies the same rules of organization. To the new institution will apply the provisions for public institutions of higher education in all cases when is not otherwise provided.

The draft states that all institutions that want to be transformed must approve the transformation in the Board of Administration. This one requires the opinion of the academic Senate. After the approval the institution creates a nonprofit organization (Foundation), which according to the NGOs legislation should be registered in Tirana Court. The foundation will present the transformation application to the Council of Ministers. This kind of institution creates a hotly debate, firstly because basically it envisions the transformation from a private entity to a public legal person. While public legal persons is defined by the Civil Code as "state institutions and enterprises, which are self-financed or financed by the state budget, as well as other public entities recognized by the law as legal persons" (Civil Code, article 25). Connection with the above definition is through the identification of independent public institution as a public entity recognized by the draft law on higher education and research as a legal person. The draft determines also the mode of creation of this category of HEl which is through a decision of the Council of Ministers. There is a kind of legal acrobatics in the creation of this HEl. Even the transformation procedure is too complicated. The need of creating a foundation makes the situation more disruptive. One question that arises is who will create the foundation in public HEls? The draft states that the Foundation is considered the founder of the new HEI. In case of transformation of a public HEI Council of Ministers will decide on the definitive transfer of property rights in favour of the Foundation. It will be the foundation to transfer the 
institution "the right to use" on all assets necessary for the activity of the HEI. It should be noted that this HEI is an independent institution and as such it should have the right of ownership and not only "the right to use" the above mentioned assets.

On one hand we should note that existing public HEls have "the right to use" on all mentioned assets and this passage of "the right to use" does not constitute an incentive for these institutions to be transformed in the independent $\mathrm{HEl}$. On the other hand we can identify two incentives for public HEl. The first incentive is related to the fact that state budget funds will be administered in accordance with the rules defined in the institution's internal regulations as well as specific conditions determined for the funds received. The second incentive is related to different composition of the Board of Administration. It decreases in this case the number of representatives from the Ministry. It is represented in this body with only one member while the founder of the institution is represented with six members (founder - foundation), and the senate is represented with four members - one of them is the rector of the institution which is a de iure member. These two elements are both important as they are elements that show in favour of a pronounced independence of this institution.

\section{Conclusions}

While the author writes this paper the draft law on higher education and research has not been analysed by the Law Commission in the Albanian Parliament. It can undergo to numerous changes until final approval. As the author analyses some changes are probably needed, within the improvement and greater effectiveness of the reform. We look forward to further developments.

\section{Reference}

Constitution of Republic of Albania, www.qpz.gov.al. Version in English in http://www.osce.org/albania/41888?download=true Decisions of the Albanian Constitutional Court no. 36, year 2007 and no. 9, year 2008.

Draft law "on Higher education and research in HEl in Republic of Albania", source - Ministry of education and Sports.

Law no. 7850, dated 29.07.1994 "on the civil code of the Republic of Albania", www.qpz.gov.al

Law no. 9741, dated 21.5.2007 "on Higher education in Republic of Albania", changed, www.qpz.gov.al 